Article

\title{
Experiment Research on Micro-/Nano Processing Technology of Graphite as Basic MEMS Material
}

\author{
Cheng Zhang ${ }^{1,2,3, * \mathbb{D}}$, Yijin Liu ${ }^{4}$, Mingge $\mathrm{Wu}^{1}$ and Ningbo Liao ${ }^{1}$ \\ 1 College of Mechanical and Electrical Engineering, Wenzhou University, Wenzhou 325035, China \\ 2 College of Mechanical and Electrical Engineering, Nanjing University of Aeronautics and Astronautics, \\ Nanjing 210016, China \\ 3 Key Laboratory of Air-driven Equipment Technology of Zhejiang Province, Quzhou University, \\ Quzhou 324000, China \\ 4 School of Materials Science and Engineering, University of Science and Technology Beijing, \\ Beijing 100083, China \\ * Correspondence: zhangcheng@wzu.edu.cn; Tel.: +86-158-6970-7966
}

Received: 10 May 2019; Accepted: 27 July 2019; Published: 31 July 2019

Featured Application: This study may promote graphite to become a basic MEMS material, which is significant for the expansion of the scope and field of MEMS applications.

\begin{abstract}
Graphite is expected to be a common choice for basic microelectromechanical-system (MEMS) material in the future. However, in order to become a basic MEMS material, it is very important for graphite to be adapted to the commonly-used micro-/nanoprocessing technology. Therefore, this paper used a directly lithography and etching process to study micro-, /nanoprocessing on graphite. The results show that the graphite surface is suitable for lithography, and that different shapes and sizes of photoresist patterns can be directly fabricated on the graphite surface. In addition, the micro-meter height of photoresist could still resist plasma etching when process nanometers height of graphite structures. Therefore, graphite with photoresist patterns were directly processed by etching, and nanometer amounts of graphite were etched. Moreover, micro-/nanoscale graphite structure with height ranges from $29.4 \mathrm{~nm}-30.9 \mathrm{~nm}$ were fabricated with about $23^{\circ}$ sidewall.
\end{abstract}

Keywords: graphite; MEMS; micro-/nanoprocessing; lithography; etching

\section{Introduction}

With the continuous maturity of micro-/nanoprocessing technology, microelectromechanical systems (MEMS) with silicon as the basic material have been rapidly developed, and are used in aviation, biological, medical, and other fields [1-3]. Moreover, researchers are investigating new basic MEMS materials to meet the special needs of different applications. For example, flexible materials such as polydimethylsiloxane and polyimide film have been investigated and used as basic materials in preparing flexible and wearable MEMS devices [4-6]. High tensile-strength material has also been invented, such as the nickel-molybdenum-tungsten alloy, which is a strong material invented by Kevin J. Hemker's team at Johns Hopkins University. It has good tensile and high-temperature resistance to meet the demand for MEMS to work in harsh environments [7]. With the continuous expansion of the scope and field of MEMS applications, researching for new basic MEMS materials, suitable for different application fields, is receiving increasing attention.

Graphite is a globally abundant mineral. It is a crystalline carbon with a hexagonal-layered-structure crystal lattice, each layer has the single-atom thickness of graphene [8]. This structure gives graphite excellent characteristics, such as conductivity, heat conduction, 
high-temperature resistance, radiation resistance, and good chemical stability. For example, Zheng et al. found that superlubricity characteristics exist between micron-sized graphite layers in the atmosphere [9]. Moreover, they illustrated the importance of superlubricity characteristic in future technological applications, such as durable nano- and micro-electromechanical devices and mechanical bearings [10]. The other important characteristics such as conductivity and good chemical stability, have made graphite an important material for electrodes in the field of fuel cells [11]. The above characteristics may enable graphite become an important choice for basic MEMS materials and contribute to graphite-based MEMS to work under harsh conditions, such as in chemical corrosion, friction, and wear. However, micro-/nanoprocessing technology is the main method to fabricate MEMS devices. Therefore, graphite needs to meet the requirements of micro-/nanoprocessing technology to become a basic MEMS material. At present, Carbon-MEMS have been proposed and studied, Gong et al. [12] proposes a method of mixing polyimide with nano-graphite particle additive to increase the releasing rate of sacrificial layer. Wang et al. [13-15] fabricated C-MEMS/NEMS structure by pyrolysis of photoresists on silicon wafers at temperatures ranging from 600 to 1100 ${ }^{\circ} \mathrm{C}$. Other researchers have used plasma-enhanced chemical vapor deposition (PECVD) to deposit nano-crystalline graphite (NCG) and apply NCG in MEM/NEM field [16,17]. Moreover, researchers have carried out micro-/nanoprocessing on graphite and constructed micro-/nanostructures. Liu et al. [18] deposited $\mathrm{SiO}_{2}$ films as a hard mask on the graphite surface, followed by lithography and etching processes on the graphite surface. Evans et al. [19] used aluminum film as a hard mask, followed by lithography and etching processes, and combined it with transfer technology to produce a 10-nanometer thick vermicular graphite. Divan et al. [20] used lithography and lift-off processes to fabricate metal microstructures on the graphite surface. Junji et al. [21-23] fabricated graphite-MEMS with titanium film as a hard mask coating on the graphite, then processed photoresist patterns on the titanium film. To the best of our knowledge, the current process of graphite etching relies on metal or metal oxide as a mask material, almost no research on the direct etching of the graphite surface after lithography is available. Moreover, no relevant research on the stability of graphic imaging during the direct lithography of the graphite surface is available. Besides, direct lithography is easier for obtaining images on MEMS than processing methods using metal as the intermediate layer. In addition, lithography of MEMS basic material is an important process step, basically become the foundation of other MEMS process technology, besides, direct lithography on MEMS basic material could improve the processing efficiency of MEMS. Therefore, stable lithography and the direct etching of basic materials are crucial in the fabrication of MEMS devices. In this paper, direct lithography on the graphite surface was investigated to analyze photoresist image stability, and the graphite with photoresist was directly etched so as to analyze the adaptability of graphite as a basic MEMS material, which may support the use of graphite to fabricate MEMS.

\section{Materials and Methods}

Optical lithography [24-27] is a parallel micro-/nanographic-imaging method that is commonly used in MEMS processing. In addition, etching process [28-31] is an important micro-/nanostructure process in MEMS and that is usually performed after lithography. Therefore, this paper investigated the direct lithography on the graphite surface via lithography to examine the stability of direct photoresist pattern imaging on the graphite surface. Furthermore, utilized the commonly used etching technique, reactive ion etching (RIE), to micro-process the graphite with photoresist patterns. First of all, we prepared photoresist patterns of different shapes and sizes on the graphite surface, for investigating the stability of direct photoresist pattern imaging on the graphite with the process show in Figure 1a-d. Therefore, a lithographic mask template that contains mask patterns of different shapes and sizes was designed and fabricated. Figure 2a and Figure S1a show the mask under an optical microscope. The mask template contained large quantities, neatly arranged shapes, and different sizes $(4-20 \mu \mathrm{m})$ of circular and square mask patterns. 


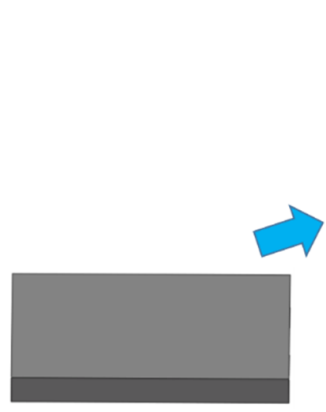

(a) Graphite

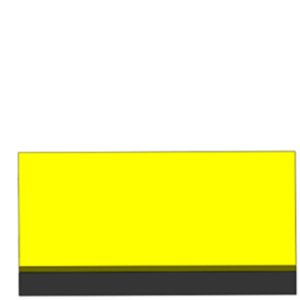

(b) Spinning
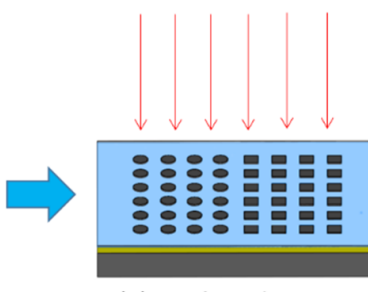

(c)Mask and exposure

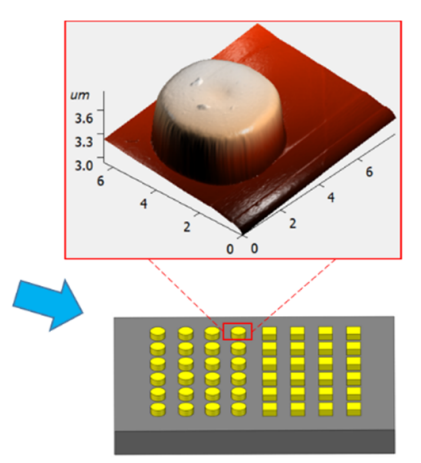

(d) Develop and bake

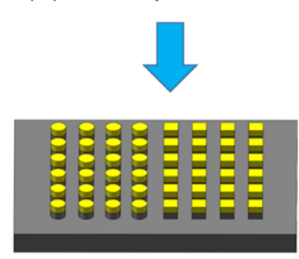

(e)Etching by RIE

(g) Graphite with microstructure

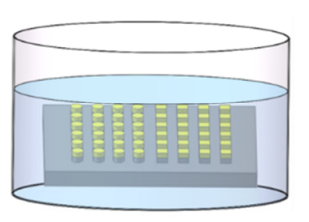

(f)Immersed in acetone
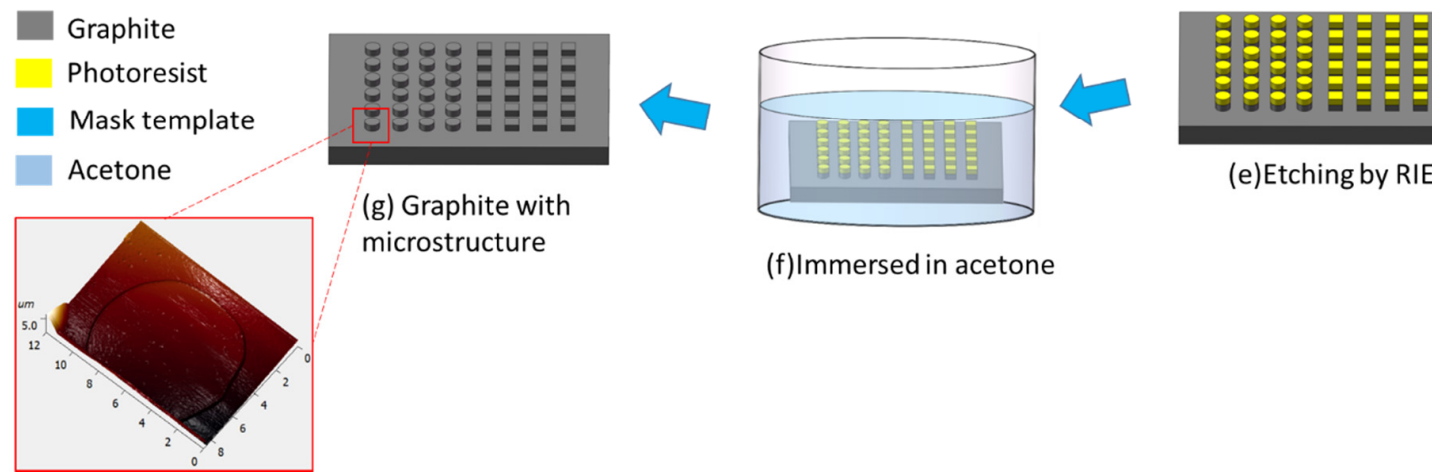

\section{(1)}



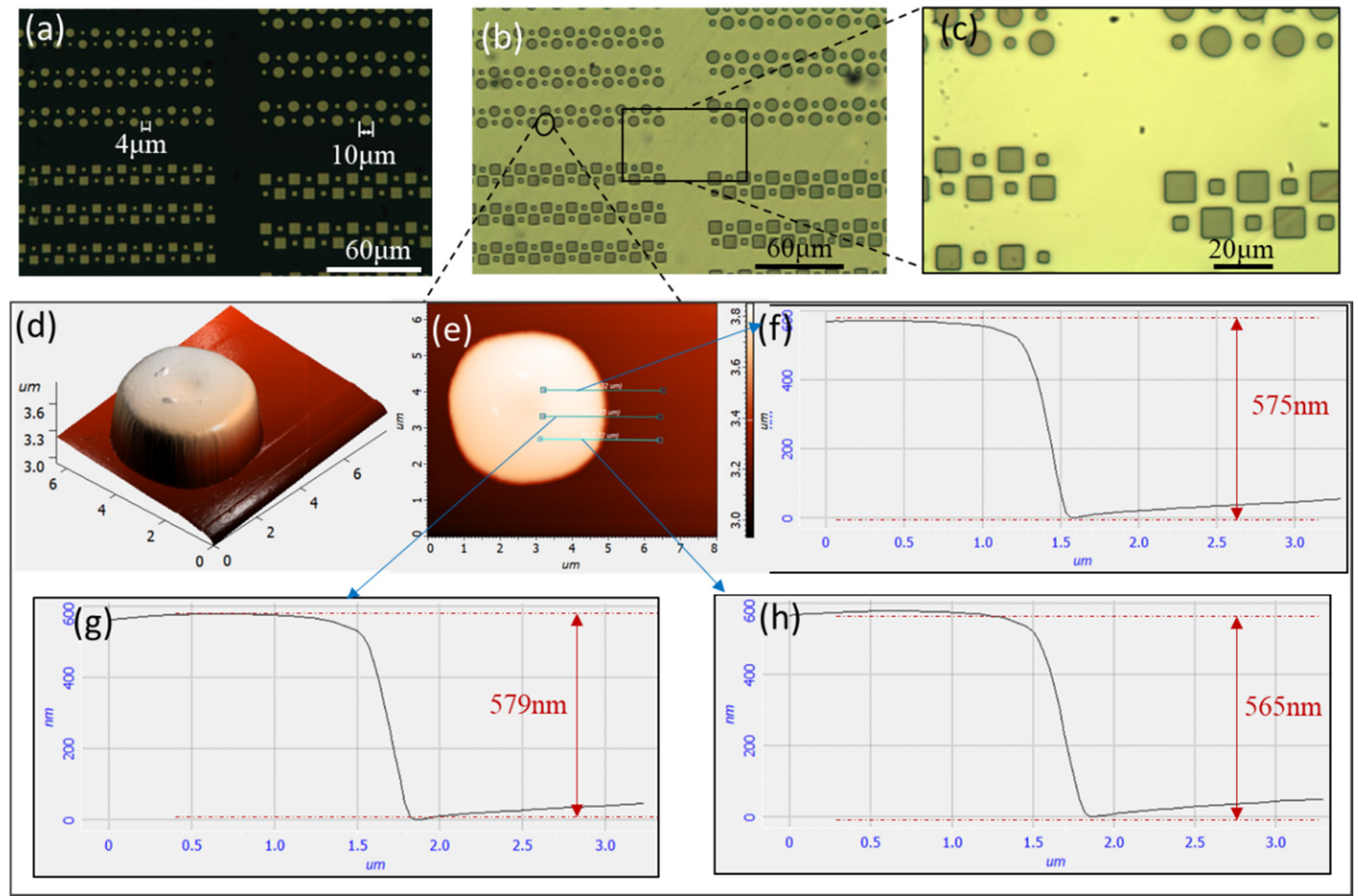

Figure 2. (a) Mask template observed under optical microscope; $(\mathbf{b}, \mathbf{c})$ photoresist patterns observed under optical microscope; $(\mathbf{d}, \mathbf{e})$ photoresist pattern observed under atomic-force microscopy; (f-h) the results of the step height characterization.

\section{Results and Discussion}

Photoresist patterns were directly processed on the graphite surface based on the aforementioned micro-/nanotechnology, shown in Figure 1a-d. In addition, Figure $2 b, c$ and Figure S1b show the photoresist patterns observed under an optical microscope. Figure $2 \mathrm{~d}-\mathrm{h}$ show the photoresist pattern observed under atomic-force microscopy (NTEGRA Solaris, T-MDT Company, Russia). As can be seen from the above Figures, lithography could be directly applied to the micrograph of the graphite surface, and photoresist patterns of different shapes and sizes can be stably and controllably processed in large quantities. Moreover, the microstructure of the photoresist processed on the graphite surface was neatly arranged. Figure $2 b-e$ shows that the height of the photoresist ranges from $565 \mathrm{~nm}-579 \mathrm{~nm}$, which means the photoresist has good height uniformity. Additionally, the photoresist pattern shown in Figure $2 b$ was processed from the mask pattern in the mask template shown in Figure 2a. The pattern comparison in Figure 2a,b shows that the photoresist pattern obtained by lithography on the graphite surface is substantially identical to the pattern on the designed mask template. This finding indicates that the graphite surface can be directly processed by lithography. Therefore, different the photoresist patterns can be designed according to requirements, and various photoresist patterns and photoresist microstructures can be accurately and controllably processed on graphite surface by optical lithography.

By using the etching process shown in Figure 1e-g, the designed microstructure pattern was machined on the graphite. Furthermore, the graphite micro-/nanostructures was characterized by atomic-force and scanning-electron microscopy. The result shows that the photoresist could still resist plasma etching before it was completely etched. As we can see from the Figure 3, part of photoresist is etched by the oxygen plasma, but most of photoresist still covered on the graphite surface with about $45^{\circ}$ sidewall. Although the oxygen plasma is also a photoresist etching, the $600 \mathrm{~nm}$ thickness photoresist still can resist the $\mathrm{O}_{2}$ etching while process tens of nanometers height of graphite structures. Moreover, we studied the amount of photoresist etched during process graphite micro-/nanostructures. The result shows that about $100 \mathrm{~nm}$ amount of photoresist etched during process about $30 \mathrm{~nm}$ amount 
of graphite. For example, a $1.06 \mu \mathrm{m}$ thickness of photoresist would have resulted in $957 \mathrm{~nm}$ thickness of photoresist left behind after etching, and a thicker thickness of photoresist would have resulted in more photoresist left behind.

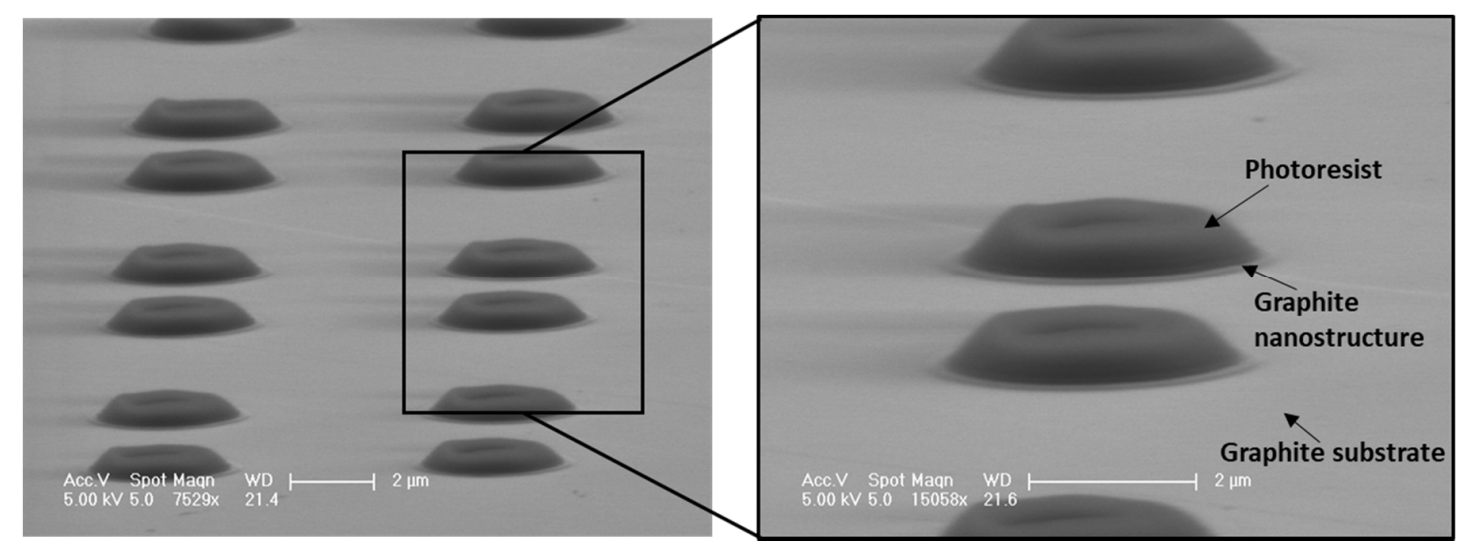

Figure 3. The electron micrograph of the etched photoresist and graphite microstructures by using scanning electron microscope.

In addition, we design experiments vary the oxygen flow rate $(20 \mathrm{sccm} ; 30 \mathrm{sccm})$, power (100 W; $150 \mathrm{~W}$ ) and pressure (7 Pa; $8 \mathrm{~Pa} ; 10 \mathrm{~Pa}$ ) to find optimum RIE conditions to fabricate graphite micro-/nano structures with larger degree sidewall. The result shows that the etch rate of the graphite changed with the different etch conditions, e.g., we could get the etch rate of $0.93 \mathrm{~nm} / \mathrm{s}$ and the $3.1 \mathrm{~nm} / \mathrm{s}$ with the parameter of $10 \mathrm{~Pa}$ chamber pressure, $100 \mathrm{~W}$ power, $20 \mathrm{sccm}$ oxygen flow rate; the etch rate of $1.2 \mathrm{~nm} / \mathrm{s}$ with the parameter of 8 Pa chamber pressure, $100 \mathrm{~W}$ power, $20 \mathrm{sccm}$ oxygen flow rate; the etch rate of $1.53 \mathrm{~nm} / \mathrm{s}$ with the parameter of $7 \mathrm{~Pa}$ chamber pressure, $100 \mathrm{~W}$ power, $20 \mathrm{sccm}$ oxygen flow rate. Therefore, the smaller the cavity pressure, the greater the etch rate of graphite. Besides, Figure 4 is the graphite nanostructures with about $23^{\circ}$ sidewall (Sentech's Etchlab 200 reactive ion etching machine; chamber pressure, $10 \mathrm{~Pa}$; power, $100 \mathrm{~W}$; oxygen flow rate, $20 \mathrm{sccm}$; etching rate $0.93 \mathrm{~nm} / \mathrm{s})$. As we can see from the Figure 4, the sidewall of the micro-/nanoscale graphite structures obtained by using the photoresist as a mask relatively close to that obtained with an intermediate mask from reference [32]. Moreover, the amount of graphite etched ranges from $29.4 \mathrm{~nm}-30.9 \mathrm{~nm}$, which means a micro-/nanoscale graphite structure we got has uniform height. Therefore, although it is quite difficult to achieve nanometer amount of graphite etched using photoresist as a mask, we found the process parameter, which is 10 Pa chamber pressure, $100 \mathrm{~W}$ power, $20 \mathrm{sccm}$ oxygen flow rate. Besides, the graphite with photoresist patterns could be fabricated by RIE to produce neatly arranged graphite micro-/nano structures. Figure 3, Figure 4a,d and Figure S2 show that circular graphite microstructure can be processed. Furthermore, Figure 4c-e shows that a processed graphite microstructure can achieve nanometer amount of graphite etched. Therefore, graphite can be directly subjected to micro-/nanoprocessing such as etching, and the micro-/nanoscale graphite structures can be stably and controllably processed, thereby illustrating that the adaptability of graphite as a basic MEMS material to micro-/nanoprocessing. 

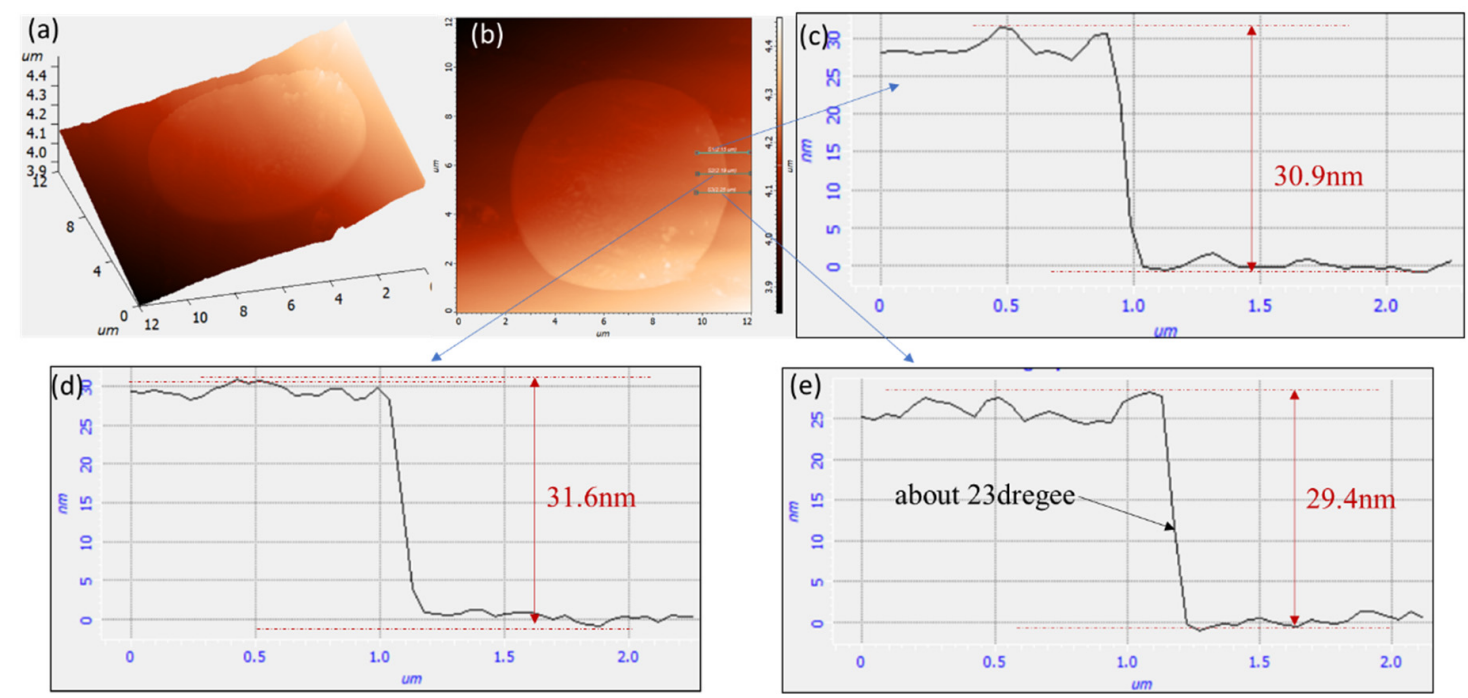

Figure 4. The fabricated graphite nanostructure with about $23^{\circ}$ sidewall $(\mathbf{a}, \mathbf{b})$ atomic-force-microscopy characterization of the graphite nanostructure; $(\mathbf{c}-\mathbf{e})$ the results of the step height characterization of the graphite nanostructure.

\section{Conclusions}

In conclusion, this paper used directly lithography and etching to study micro-/nanoprocessing on graphite. The results show that graphite can be directly processed by lithography and different mask patterns can be designed according to requirements. Moreover, various photoresist patterns can be accurately and controllably processed on graphite with uniform height, and graphite with photoresist patterns can be directly processed by etching nanometer amount to form micro-/nanoscale graphite structures. In addition, the micro-meter height photoresist could resist plasma etching when process nanometers height of graphite structures. Moreover, graphite with photoresist patterns has been directly processed by etching, and nanometer amounts of graphite have been etched. Micro-/nanoscale graphite structures with height range from $29.4 \mathrm{~nm}-30.9 \mathrm{~nm}$ was fabricated. Furthermore, a greater thickness of photoresist would have resulted in more photoresist left behind. Therefore, this study proves that graphite can be compatible with common micro-/nanoprocessing techniques, and may supports the use of graphite to fabricate MEMS, which is important for graphite applications.

Supplementary Materials: The following are available online at http://www.mdpi.com/2076-3417/9/15/3103/s1, Figure S1 (a) photograph of the mask template observed under an optical microscope (b) photographs of the photoresist patterns observed under an optical microscope, Figure S2 the electron micrograph of the etched photoresist and graphite microstructure.

Author Contributions: C.Z. conceived and designed the study; N.L. analyzed the experimental data; C.Z. wrote the paper; M.W. and provided guidance and modification of the paper. Y.L. did some experiments and characterization of atomic-force-microscopy and scanning electron microscope.

Funding: This paper is funded by the basic scientific research project of Wenzhou, China (No. G20190014).

Acknowledgments: This paper is supported by Key Laboratory of Air-driven Equipment Technology of Zhejiang Province and the basic scientific research project of Wenzhou, China.

Conflicts of Interest: The authors declare no conflict of interest.

\section{References}

1. Pengwang, E.; Rabenorosoa, K.; Rakotondrabe, M.; Andreff, N. Scanning micromirror platform based on MEMS technology for medical application. Micromachines 2016, 7, 24. [CrossRef] [PubMed]

2. Bouchaala, A.M.; Younis, M.I. A Model of Electrostatically Actuated MEMS and Carbon Nanotubes Resonators for Biological Mass Detection. In Design and Modeling of Mechanical Systems-II; Springer: Cham, Switzerland, 2015; pp. 501-512. 
3. Jia, Y.; Li, S.; Qin, Y.; Cheng, R. Error analysis and compensation of MEMS rotation modulation inertial navigation system. IEEE Sens. J. 2018, 18, 2023-2030. [CrossRef]

4. Ge, C.; Cretu, E. A sacrificial-layer-free fabrication technology for MEMS transducer on flexible substrate. Sens. Actuators A Phys. 2019, 286, 202-210. [CrossRef]

5. Zhao, C.; Knisely, K.E.; Grosh, K. Design and fabrication of a piezoelectric MEMS xylophone transducer with a flexible electrical connection. Sens. Actuators A Phys. 2018, 275, 29-36. [CrossRef]

6. Zhang, L.; Jiang, Y.; Liu, B.; Zhang, M.; Pang, W. Highly flexible piezoelectric MEMS resonators encapsulated in polymer thin films. In Proceedings of the 2018 IEEE Micro Electro Mechanical Systems (MEMS), Belfast, UK, 21-25 January 2018; IEEE: Piscataway, NJ, USA, 2018; pp. 170-173.

7. Sim, G.D.; Krogstad, J.A.; Reddy, K.M.; Xie, K.Y.; Valentino, G.M.; Weihs, T.P.; Hemker, K.J. Nanotwinned metal MEMS films with unprecedented strength and stability. Sci. Adv. 2017, 3, e1700685. [CrossRef] [PubMed]

8. Gongyang, Y.; Qu, C.; Zhang, S.; Ma, M.; Zheng, Q. Eliminating delamination of graphite sliding on diamond-like carbon. Carbon 2018, 132, 444-450. [CrossRef]

9. Deng, H.; Ma, M.; Song, Y.; He, Q.; Zheng, Q. Structural superlubricity in graphite flakes assembled under ambient conditions. Nanoscale 2018, 10, 14314-14320. [CrossRef]

10. Hod, O.; Meyer, E.; Zheng, Q.; Urbakh, M. Structural superlubricity and ultralow friction across the length scales. Nature 2018, 563, 485-492. [CrossRef]

11. Zhou, M.; Chi, M.; Luo, J.; He, H.; Jin, T. An overview of electrode materials in microbial fuel cells. J. Power Sources 2011, 196, 4427-4435. [CrossRef]

12. Gong, Z.; Liu, Z. Fast MEMS releasing with polymer and nano-graphite particle additive. In Proceedings of the 2016 China Semiconductor Technology International Conference (CSTIC), Shanghai, China, 13-14 March 2016; IEEE: Piscataway, NJ, USA, 2016; pp. 1-3.

13. Wang, C.; Zaouk, R.; Malladi, K.; Taherabadi, L.; Madou, M. C-MEMS/NEMS: A Novel Technology for Nanoscale Material Formation from Graphite Fiber to Ni and Si Nanowires. In Proceedings of the ASME 2004 3rd Integrated Nanosystems Conference, Pasadena, CA, USA, 22-24 September 2004; American Society of Mechanical Engineers: New York, NY, USA, 2004; pp. 133-134.

14. Kim, J.; Song, X.; Kinoshita, K.; Madou, M.; White, R. Electrochemical studies of carbon films from pyrolyzed photoresist. J. Electrochem. Soc. 1998, 145, 2314-2319. [CrossRef]

15. Ranganathan, S.; Mccreery, R.; Majji, S.M.; Madou, M. Photoresist-derived carbon for microelectromechanical systems and electrochemical applications. J. Electrochem. Soc. 2000, 147, 277-282. [CrossRef]

16. Fishlock, S.J.; O'Shea, S.J.; McBride, J.W.; Chong, H.M.; Pu, S.H. Fabrication and characterisation of nanocrystalline graphite MEMS resonators using a geometric design to control buckling. J. Micromech. Microeng. 2017, 27, 095015. [CrossRef]

17. Rana, S.; Reynolds, J.D.; Ling, T.Y.; Shamsudin, M.S.; Pu, S.H.; Chong, H.M.; Pamunuwa, D. Nano-crystalline graphite for reliability improvement in MEM relay contacts. Carbon 2018, 133, 193-199. [CrossRef]

18. Liu, Z.; Yang, J.; Grey, F.; Liu, J.Z.; Liu, Y.; Wang, Y.; Yang, Y.; Cheng, Y.; Zheng, Q. Observation of microscale superlubricity in graphite. Phys. Rev. Lett. 2012, 108, 205503. [CrossRef] [PubMed]

19. Evans, J.S.; Guo, T.; Sun, Y.; Liu, W.; Peng, L.; Xu, Z.; Gao, C.; He, S. Shape-controlled tens-nanometers-thick graphite and worm-like graphite through lithographic exfoliation. Carbon 2018, 135, 248-252. [CrossRef]

20. Divan, R.; Mancini, D.; Gallagher, S.; Booske, J.; Van Der Weide, D. Improvements in graphite-based X-ray mask fabrication for ultradeep X-ray lithography. Microsyst. Technol. 2004, 10, 728-734. [CrossRef]

21. Sone, J.; Murakami, M.; Tatami, A. Fundamental Study for a Graphite-Based Microelectromechanical System. Micromach. 2018, 9, 64. [CrossRef]

22. Sone, J. Feasible Development of a Carbon-Based MEMS Using a MEMS Fabrication Process. J. Chem. Chem. Eng. 2014, 8, 1082-1088.

23. Sone, J.; Shigeta, N.; Yamada, K.; Uchida, T.; Yoshida, S.; Hayasaka, T.; Tanaka, S. Annealing Transformation of Diamond-Like Carbon Using Ni Catalyst. Jpn. J. Appl. Phys. 2013, 52, 128005. [CrossRef]

24. Zhang, C.; Wen, D.; Zhu, H.; Zhang, X.; Yang, X.; Shi, Y.; Zheng, T. Micro-fabrication method of graphite mesa microdevices based on optical lithography technology. J. Micromech. Microeng. 2017, 27, 125022. [CrossRef]

25. Bose, S.; Cunha, J.M.V.; Suresh, S.; De Wild, J.; Lopes, T.S.; Barbosa, J.R.S.; Silva, R.; Borme, J.; Fernandes, P.A.; Vermang, B.; et al. Optical Lithography Patterning of $\mathrm{SiO}_{2}$ Layers for Interface Passivation of Thin Film Solar Cells. Sol. RRL 2018, 2, 1800212. [CrossRef] 
26. Minaev, N.V.; A Tarkhov, M.; Dudova, D.S.; Timashev, P.S.; Chichkov, B.N.; Bagratashvili, V.N. Fabrication of superconducting nanowire single-photon detectors by nonlinear femtosecond optical lithography. Laser Phys. Lett. 2018, 15, 026002. [CrossRef]

27. Nguyen, D.T.T.; Del Guercio, O.; Au, T.H.; Trinh, D.T.; Mai, N.P.T.; Lai, N.D. Optical lithography of three-dimensional magnetophotonic microdevices. Opt. Eng. 2018, 57, 041406. [CrossRef]

28. Dowling, K.M.; Ransom, E.H.; Senesky, D.G. Profile evolution of high aspect ratio silicon carbide trenches by inductive coupled plasma etching. J. Microelectromech. Syst. 2017, 26, 135-142. [CrossRef]

29. Lutker-Lee, K.M.; Lu, Y.T.; Lou, Q.; Kaminsky, J.; Kikuchi, Y.; Raley, A. Low-k dielectric etch challenges at the $7 \mathrm{~nm}$ logic node and beyond: Continuous-wave versus quasiatomic layer plasma etching performance review. J. Vac. Sci. Technol. A Vac. Surf. Film. 2019, 37, 011001. [CrossRef]

30. Fitzgerald, M.L.; Tsai, S.; Bellan, L.M.; Sappington, R.; Xu, Y.; Li, D. The relationship between the Young's modulus and dry etching rate of polydimethylsiloxane (PDMS). Biomed. Microdevices 2019, 21, 26. [CrossRef]

31. Wu, J.; Ye, X.; Sun, L.; Huang, J.; Wen, J.; Geng, F.; Zeng, Y.; Li, Q.; Yi, Z.; Jiang, X.; et al. Growth mechanism of one-step self-masking reactive-ion-etching (RIE) broadband antireflective and superhydrophilic structures induced by metal nanodots on fused silica. Opt. Express 2018, 26, 1361-1374. [CrossRef]

32. Liu, Z.; Liu, J.Z.; Cheng, Y.; Li, Z.; Wang, L.; Zheng, Q. Interlayer binding energy of graphite: A mesoscopic determination from deformation. Phys. Rev. B 2012, 85, 205418. [CrossRef]

(C) 2019 by the authors. Licensee MDPI, Basel, Switzerland. This article is an open access article distributed under the terms and conditions of the Creative Commons Attribution (CC BY) license (http://creativecommons.org/licenses/by/4.0/). 